\title{
CD14 C-260T gene polymorphism and ischemic heart disease susceptibility: A HuGE review and meta-analysis
}

\author{
Hai-Feng Zhang, $M D^{I}$, Bao-Liang Zhong, $M D^{2}$, Wa-Li Zhu, $M D^{I}$, Shuang-Lun Xie, MD, PhD , \\ Li-Xin Qiu, MD ${ }^{4}$, Li-Guang Zhu, $M D^{I}$, Yan Wang, MD, PhD ${ }^{I}$, and Lei Lei, $M D^{I}$
}

\begin{abstract}
The $C D 14$ gene C-260T polymorphism has been reported to be associated with ischemic heart disease, but results were conflicting. To evaluate the role of the $C D 14 \mathrm{C}-260 \mathrm{~T}$ polymorphism in ischemic heart disease, we performed meta-analyses of all available data. Comprehensive searches for studies on the association between the genotypes (CC, CT, TT) distributions and ischemic heart disease risk were performed. Patients with acute coronary syndrome, prior myocardial infarction, stable angina pectoris, or angiographic coronary artery stenosis were included. Potential sources of heterogeneity were explored by meta-regression. Analyses were performed under European, East Asian, and Indian studies, respectively. Data were available for 19 studies involving 11,813 cases and 6,196 controls. The summary odds ratio under the recessive model was $1.53(95 \%$ confidence interval: 1.20-1.96) for East Asian studies published in English language journals on overall ischemic heart disease. Pooled odds ratios under the codominant model were about 1.81 (95\% confidence interval: 1.36-2.40) and 1.70 (95\% confidence interval: 1.26-2.29) for Chinese studies on overall ischemic heart disease and other ischemic heart disease (angina pectoris and angiographic coronary artery stenosis), respectively. No significant association was found in a European population, an Indian population, or the vulnerable plaque ischemic heart disease (acute coronary syndrome and prior myocardial infarction) subgroup of an East Asian population. It is probable that T allele and TT genotype are associated with ischemic heart disease in the East Asian population but not in the European or Indian populations. Further studies are warranted to assess these associations in greater details, especially in East Asian and Indian populations. Genet Med 2009:11(6):403-408.
\end{abstract}

Key Words: CD14, ischemic heart disease, polymorphism, susceptibility, meta-analysis

A therosclerosis is a partly heritable disorder, ${ }^{1}$ although the genes nvolved and the associated risks are still unclear. ${ }^{2}$ Ischemic heart disease (IHD) is a group of diseases mainly caused by

\footnotetext{
From the ${ }^{1}$ Department of Cardiology, Institute of Cardiovascular Diseases, First Affiliated Hospital, Guangxi Medical University, Guangxi, China; ${ }^{2}$ Wuhan Mental Health Center, Tongji Medical College of Huazhong University of Science and Technology, Wuhan, China; ${ }^{3}$ Department of Cardiology, The Second Affiliated Hospital of Sun Yat-Sen University, Guangzhou, China; and ${ }^{4}$ Department of Medical Oncology, Shanghai Medical College, Cancer Hospital, Fudan University, Shanghai, China.

Li-Guang Zhu, MD, Department of Cardiology, Institute of Cardiovascular Diseases, First Affiliated Hospital, Guangxi Medical University, Nanning, GuangXi 530021, China. E-mail: dr.liguang.zhu@gmail.com.

The first two authors contributed equally to this work
}

Supplemental digital content is available for this article. Direct URL citations appear in the printed text and are provided in the HTML and PDF versions of this article on the journal's Web site (www.geneticsinmedicine.org).

Disclosure: The authors declare no conflict of interest

Submitted for publication October 19, 2008

Accepted for publication February 17, 2009

Published online ahead of print April 2, 2009.

DOI: 10.1097/GIM.0b013e3181a16cb0 coronary atherosclerosis. It is widely accepted that inflammation and infection play a key role in atherosclerosis and IHD. ${ }^{3-6} \mathrm{Im}-$ mune cells are thought to be involved in many aspects related to IHD (e.g., lipoprotein retention and activation of oxidized lowdensity lipoprotein, plaque development and rupture) and dominate the atherosclerotic lesions. ${ }^{6}$ Infection has also been reported to be involved in inflammation and plaque activation, thus infection affects the progressions of atherosclerosis and IHD and elicits clinical symptoms. ${ }^{6}$ The $C D 14$ gene has been proposed as a susceptibility gene for IHD. ${ }^{7}$ It is located on chromosome $5 \mathrm{q} 31$ and encodes CD14, a protein which is a component of lipopolysaccharide receptor complex mainly expressed by monocytes and macrophages. ${ }^{8}$ By binding to lipopolysaccharide, CD14 mediates the activation of inflammatory cells and is thus involved in inflammatory reactions and contributes to the production of inflammatory mediators and cytokines. ${ }^{9}$

\section{GENE VARIANT}

Baldini et al. ${ }^{10}$ first reported the existence of a single nucleotide polymorphism in the $5^{\prime}$ genomic region of CDI4 at position -260 (allele $\mathrm{C}$ and $\mathrm{T}$ ) with respect to the translation start site ( -159 when counting from the transcription start site) and found that the frequencies of the two alleles were similar in the white population from Tucson. The -260T allele was soon reported to be associated with myocardial infarction (MI). ${ }^{7}$ The substitution of $\mathrm{C} \rightarrow \mathrm{T}$ leads to an increased transcriptional activity, which is paralleled by a decreased affinity of DNA/ protein interactions between the $\mathrm{Sp} 1,2,3$ proteins and the GC box in the CD14 promoter. This may be important for the pathogenesis of inflammatory diseases. ${ }^{11} \mathrm{~A}$ higher expression of CD14 on the surface of monocytic lineage cells has been observed in TT homozygotes carriers. ${ }^{7,10}$ All of these lead to the hypothesis that the increased activity of the CD14 promoter results in a higher expression of CD14, hence triggers production of inflammatory cytokines and increases IHD risk.

\section{OBJECTIVES}

Many studies have been carried out to investigate the association between the $C D 14 \mathrm{C}-260 \mathrm{~T}$ polymorphism and IHD risk, but the results were inconsistent. This may be partly because of small sample size, different IHD endpoints (e.g., MI and angiographic coronary artery stenosis [CAS]), and different populations (e.g., European, East Asian, and others). Demonstration of an association may require a much larger number of subjects, which may be beyond the resources of one single study site. IHD continues to be the leading cause of morbidity and mortality worldwide, affecting about $9.4 \%$ US white men, $6.0 \%$ US white women, $3.8 \%$ Asians, and $2.5 \%$ American Indians. ${ }^{12} \mathrm{We}$ thus conducted meta-analyses of all available data in accordance with the guidelines of the Human Genome Epidemiology Network (HuGENet $\left.{ }^{\mathrm{TM}}\right)^{13,14}$ to clarify the role of the CD14 C-260T polymorphism in IHD. To help elucidate the gene effect 
in different ethnicities, we performed the analyses based on ethnicities. ${ }^{15}$

\section{METHOD}

\section{Selection criteria}

For inclusion, studies had to be case-controlled or cohort in design, use proper IHD diagnosis criteria (e.g., angiographically confirmed; elevations of cardiac enzymes, changes of electrocardiographic and clinical symptoms according to the World Health Organizations criteria; a documented history of coronary artery bypass graft, percutaneous transluminal coronary angioplasty, or percutaneous coronary intervention), involve unrelated participants, and examine the association between IHD and the presence of CD14 C-260T polymorphism. IHD was defined as acute coronary syndrome (ACS), prior MI, stable angina pectoris (AP), and angiographic CAS. ${ }^{16-18}$ If essential information of a study was not presented, authors were contacted for details. The study would be excluded if the information could not be obtained.

\section{Search strategy}

All studies reporting the association between the CD14 C-260T polymorphism and IHD risk published before December 2008 were identified by comprehensive computer-based searches of Medline, EMBase, BIOSIS, Global Health, LILACS (http://bases.bireme.br), CBMDisc (http://cbmwww. imicams.ac.cn), and HuGENet. ${ }^{19}$ Terms used for the searches were "CD14," "ischemic heart disease," "coronary heart disease," "coronary artery disease," "acute coronary syndrome," "myocardial infarction," and "angina pectoris," combined with "gene," "genetic," "variant," "mutation," or "polymorphism." Hand searches for related articles were also performed.

\section{Data extraction}

The first author, published year, country, populations, mean age of participants, study design, sample size, outcome, diagnostic criteria, genotyping method, characteristics of the controls, allele frequencies, genotype distributions, and cardiovascular risk factors were extracted independently by two authors (H.-F.Z. and B.-L.Z.). Results were then compared, and disagreements were resolved by discussion.

\section{Quality score assessment}

The quality of included studies was assessed independently by the same two authors using modified quality assessment scores reported previously. ${ }^{20}$ Dissensions were resolved by discussion. Scores ranged from 0 (lowest) to 13 (highest).

\section{Statistical analysis}

First, deviance from Hardy-Weinberg equilibrium (HWE) was assessed for the controls of each study using Fisher's exact test. Second, genotype distributions of controls were used to estimate the frequency of the putative risk allele $(-260 \mathrm{~T})$ in various ethnic groups (if the ethnicity of participants was not indicated in the study, ethnicity was assumed according to geographical location from which the participants were recruited) using the inverse variance method. ${ }^{20}$ Third, estimation of the gene effect on IHD was performed by a logistic regression approach described previously. ${ }^{21}$ Briefly, a Cochrane Qtest $^{22}$ for heterogeneity with a significance level of $P<0.1$ rather than 0.05 was used separately for three odds ratios (ORs): TT versus $\mathrm{CC}\left(\mathrm{OR}_{1}\right), \mathrm{CT}$ versus $\mathrm{CC}\left(\mathrm{OR}_{2}\right)$, and TT versus CT $\left(\mathrm{OR}_{3}\right)$. If there was heterogeneity on at least one of the three
ORs, the sources of heterogeneity were explored by fitting a covariable (e.g., ethnicity, sample size, published language, outcome, or quality score) in the meta-regression model. ${ }^{23-25}$ If there was no heterogeneity, logistic regression with the fixed-effects model was used to evaluate the overall gene effect; or else, the random-effects model was used. A likelihood ratio (LR) test, but not the three ORs, was used to estimate whether the overall gene effect was significant. If a significant overall gene effect was observed, further comparisons of $\mathrm{OR}_{1}$, $\mathrm{OR}_{2}$, and $\mathrm{OR}_{3}$ were made and the indicated genetic models were selected as follows:

1. Dominant model if $\mathrm{OR}_{1}=\mathrm{OR}_{2} \neq 1$ and $\mathrm{OR}_{3}=1$.

2. Recessive model if $\mathrm{OR}_{1}=\mathrm{OR}_{3} \neq 1$ and $\mathrm{OR}_{2}=1$.

3. Overdominant model if $\mathrm{OR}_{2}=1 / \mathrm{OR}_{3} \neq 1$ and $\mathrm{OR}_{1}=1$.

4. Codominant model if $\mathrm{OR}_{1}>\mathrm{OR}_{2}>1$ and $\mathrm{OR}_{1}>\mathrm{OR}_{3}>$ 1 (or $\mathrm{OR}_{1}<\mathrm{OR}_{2}<1$ and $\mathrm{OR}_{1}<\mathrm{OR} 3<1$ ).

Finally, once the appropriate genetic model was identified, results were pooled again under this genetic model.

Publication bias was assessed using Egger's test. ${ }^{26}$ In addition, subgroup analysis based on whether the IHD was related to vulnerable plaque or not was performed. ${ }^{27-29} \mathrm{ACS}$ and prior MI were defined as vulnerable plaque IHD, whereas AP and angiographic CAS were indicated as other IHD. ${ }^{27-29}$ Sensitivity analysis was carried out by including studies that deviated from HWE.

All analyses were performed using STATA software, version 9.2 (StataCorp. 2005. Stata Statistical Software: Release 9. College Station, TX: StataCorp LP).

\section{RESULTS}

\section{Study inclusion and characteristics}

The combined searches yielded 603 records. Of the 603, 531 were excluded by reading titles and abstracts. Finally, 19 studies were included. $7,27,30-46$ One Chinese study ${ }^{47}$ met the inclusion criteria but was excluded, because the author obviously misunderstood the locus and no additional information could be obtained by contacting authors. One European study ${ }^{7}$ was used only for sensitivity analysis because both the cases and the controls in this study might overlap with the latter study by Lorenzova et al., ${ }^{45}$ which had a larger sample size. $7,45,48$

All the included studies used either case-control or nested case-control design. ACS, prior MI, AP, and angiographic CAS cases were included. Appropriate diagnosis criteria and proper genotyping methods were used in most of the studies. Of the 19 studies, 11 involved European populations, ${ }^{7,30-34,36,38,39,41,45}$ one involved an Indian population, ${ }^{43}$ and seven involved East Asian populations, ${ }^{27,35,37,40,42,44,46}$ of which five were published in Chinese journals. ${ }^{37,40,42,44,46}$ Fourteen studies involved vulnerable plaque IHD patients. Of the 14, 10 included European populations, ${ }^{7,30-32,34,36,38,39,41,45}$ one included an Indian population, ${ }^{43}$ and three included East Asian populations, ${ }^{27,35,40}$ of which one was published in a Chinese journal. ${ }^{40}$ Twelve studies involved other IHD cases, including six involving European populations $\mathrm{s}^{30,32-34,38,39}$ and six involving East Asian populations, $27,37,40,42,44,46$ of which five were published in Chinese journals. ${ }^{37,40,42,44,46}$ Genotype distributions deviated from HWE in one study. ${ }^{42}$ The characteristics of included studies are listed in Table 1 , and the sources of participants, as well as the geographic location of the studies, are listed in Supplemental Table, Supplemental Digital Content 1, http://links.lww.com/A842. 
Table 1 Characteristics of eligible studies in the meta-analysis

\begin{tabular}{|c|c|c|c|c|c|c|c|c|c|c|c|c|c|}
\hline \multirow[b]{3}{*}{ Study } & \multirow[b]{3}{*}{ Country } & \multirow[b]{3}{*}{ Design } & \multicolumn{4}{|c|}{ Cases } & \multicolumn{4}{|c|}{ Control } & \multirow{3}{*}{$\begin{array}{c}\text { HWE } \\
P\end{array}$} & \multirow[b]{3}{*}{ Outcome } & \multirow[b]{3}{*}{ Score } \\
\hline & & & \multirow[b]{2}{*}{$N$} & \multicolumn{3}{|c|}{ Genotypes } & \multirow[b]{2}{*}{$N$} & \multicolumn{3}{|c|}{ Genotypes } & & & \\
\hline & & & & $\mathrm{CC}$ & $\mathrm{CT}$ & $\mathrm{TT}$ & & $\mathrm{CC}$ & $\mathrm{CT}$ & TT & & & \\
\hline \multicolumn{14}{|l|}{ European } \\
\hline Zee et al. ${ }^{31}$ & America & $\mathrm{NCC}$ & 387 & 98 & 215 & 74 & 387 & 108 & 193 & 86 & 1.00 & MI & 12 \\
\hline Hubacek et al. ${ }^{a}$ & $\mathrm{CZ}$ & $\mathrm{CC}$ & 178 & 52 & 77 & 49 & 135 & 61 & 53 & 21 & 0.13 & MI & 6 \\
\hline Lorenzova et al. ${ }^{45}$ & $\mathrm{CZ}$ & $\mathrm{CC}$ & 230 & 63 & 116 & 51 & 562 & 166 & 268 & 128 & 0.35 & AMI & 4 \\
\hline Espliguro et al. ${ }^{39}$ & England & $\mathrm{CC}$ & 334 & 79 & 163 & 92 & 94 & 31 & 42 & 21 & 0.40 & ACS, CSA & 12 \\
\hline Morange et al. ${ }^{41}$ & England & $\mathrm{CC}$ & 54 & 12 & 28 & 14 & 70 & 24 & 31 & 15 & 0.47 & MI & 8 \\
\hline Morange et al. ${ }^{41}$ & FR & $\mathrm{CC}$ & 99 & 20 & 57 & 22 & 121 & 29 & 53 & 39 & 0.20 & MI & 8 \\
\hline Morange et al. ${ }^{38}$ & FR, NIE & $\mathrm{NCC}$ & 128 & 43 & 59 & 26 & 253 & 69 & 113 & 71 & 0.10 & MI & 13 \\
\hline Morange et al. ${ }^{38}$ & FR, NIE & $\mathrm{NCC}$ & 123 & 31 & 58 & 34 & 243 & 61 & 124 & 58 & 0.80 & $\mathrm{AP}$ & 13 \\
\hline Unkelback et al..$^{30}$ & Germany & $\mathrm{CC}$ & 1727 & 491 & 864 & 372 & 501 & 140 & 240 & 121 & 0.37 & MI, CAD & 12 \\
\hline Koch et al. ${ }^{32}$ & Germany & $\mathrm{CC}$ & 1791 & 505 & 888 & 398 & 340 & 88 & 177 & 75 & 0.51 & MI, CAD & 12 \\
\hline Koenig et al. ${ }^{33}$ & Germany & $\mathrm{CC}$ & 312 & 75 & 164 & 73 & 476 & 126 & 243 & 107 & 0.65 & CAD & 11 \\
\hline Nauck et al. ${ }^{34}$ & Germany & $\mathrm{NCC}$ & 4158 & 1119 & 2020 & 1019 & 697 & 188 & 358 & 151 & 0.45 & MI, CAD & 8 \\
\hline Longobardo et al. ${ }^{36}$ & Italy & $\mathrm{CC}$ & 215 & 44 & 101 & 70 & 215 & 55 & 101 & 59 & 0.41 & AMI & 12 \\
\hline Morange et al. ${ }^{41}$ & Italy & $\mathrm{CC}$ & 194 & 42 & 98 & 54 & 197 & 39 & 104 & 54 & 0.47 & MI & 8 \\
\hline Morange et al. ${ }^{41}$ & Sweden & $\mathrm{CC}$ & 179 & 60 & 94 & 25 & 176 & 65 & 77 & 34 & 0.21 & MI & 8 \\
\hline Subtotal & & & 10,109 & 2734 & 5002 & 2373 & 4467 & 1250 & 2177 & 1040 & & & \\
\hline \multicolumn{14}{|l|}{ East Asian } \\
\hline Shimada et al. ${ }^{27}$ & Japan & $\mathrm{CC}$ & 128 & 27 & 49 & 52 & 83 & 21 & 43 & 19 & 0.83 & AMI, AP & 9 \\
\hline Hohda et al. ${ }^{35}$ & Japan & $\mathrm{CC}$ & 502 & 97 & 242 & 163 & 527 & 115 & 278 & 134 & 0.22 & MI & 8 \\
\hline Pan et al..$^{37 b}$ & $\mathrm{PRC}$ & $\mathrm{CC}$ & 50 & 14 & 21 & 15 & 90 & 45 & 31 & 14 & 0.05 & CAD & 5 \\
\hline Li et al. $40^{b}$ & PRC & $\mathrm{CC}$ & 162 & 24 & 75 & 63 & 196 & 54 & 89 & 53 & 0.20 & MI, CAD & 8 \\
\hline $\mathrm{Hu}$ et al. ${ }^{42 b}$ & PRC & $\mathrm{CC}$ & 218 & 48 & 57 & 113 & 227 & 117 & 39 & 71 & $<0.01$ & CAD & 5 \\
\hline $\mathrm{Li}$ et al. ${ }^{44 b}$ & PRC & $\mathrm{CC}$ & 193 & 29 & 95 & 69 & 225 & 47 & 124 & 54 & 0.14 & CAD & 5 \\
\hline Xie et al. ${ }^{46^{b}}$ & PRC & $\mathrm{CC}$ & 241 & 49 & 127 & 65 & 149 & 56 & 65 & 28 & 0.24 & CAD & 5 \\
\hline Subtotal & & & 1494 & 288 & 684 & 540 & 1497 & 455 & 669 & 373 & & & \\
\hline \multicolumn{14}{|l|}{ Indian } \\
\hline Banerjee et al. ${ }^{43}$ & India & $\mathrm{CC}$ & 210 & 45 & 116 & 49 & 232 & 38 & 126 & 68 & 0.14 & MI, UA & 7 \\
\hline Total & & & 11,813 & 3067 & 5802 & 2962 & 6196 & 1743 & 2972 & 1481 & & & \\
\hline
\end{tabular}

${ }^{a}$ The study was used in sensitivity analysis.

${ }^{b}$ These articles were published in Chinese.

$N$, sample size; HWE, Hardy-Weinberg Equilibrium; CC, case-control; NCC, nested case-control; MI, myocardial infarction; CAD, coronary artery disease; AMI, acute myocardial infarction; ACS, acute coronary syndrome; CSA, chronic stable angina; AP, angina pectoris; UA, unstable angina; CZ, Czech Republic; FR, France; NIE, Northern Ireland; PRC, People's Republic of China.

\section{Pooled prevalence of CD14-260T in the controls}

The -260T allele frequency could be obtained in all included studies. Two European studies reported two ${ }^{38}$ and four subgroups $^{41}$ containing different control subjects, respectively.

There was no heterogeneity among the 10 European population studies $\left(\chi_{13}^{2}=11.01, P=0.61\right)$. The pooled frequency using the fixed-effects model was $48.03 \%$ (95\% confidence interval [CI]: 46.54-49.51\%); a sensitivity analysis including the study by Hubacek et al. ${ }^{7}$ showed a similar result $(47.60 \%$ [95\% CI: 46.14-49.07]). The pooled $-260 \mathrm{~T}$ frequencies were 46.88\% (95\% CI: 41.41-52.36\%), 51.39\% (95\% CI: $47.43-$ $55.36 \%$ ), and $45.70 \%$ (95\% CI: $36.48-52.62 \%$ ) for overall East Asian studies (random-effects model; $\chi_{5}^{2}=17.21, P<0.01$ ), East Asian studies published in English language journals ${ }^{27,35}$ (fixed-effects model; $\chi_{1}^{2}=0.26, P=0.61$ ) and Chinese studies $37,40,44,46$ (random-effects model; $\chi_{3}^{2}=12.80, P<0.01$ ), 
respectively. An inclusion of the study by $\mathrm{Hu}$ et $\mathrm{al} .{ }^{42}$ did not change the result significantly. The $-260 \mathrm{~T}$ allele frequency was $56.47 \%$ (95\% CI: $50.09-62.85 \%$ ) in Indian population. ${ }^{43}$

\section{Association between CD14 C-260T polymorphism and IHD risk}

\section{Meta-analysis of European studies}

All included studies reported the association between genotype distributions and IHD risk. The summary $\mathrm{OR}_{1} / \mathrm{OR}_{2} / \mathrm{OR}_{3}$ and Q-test results are listed in Table 2. No significant heterogeneity for $\mathrm{OR}_{1}, \mathrm{OR}_{2}$, or $\mathrm{OR}_{3}$ was detected among the 10 European descent studies. The logistic regression with the fixed-effects model comprised 14,263 subjects yielded a nonsignificant overall gene effect $\left(\mathrm{LR}_{2}=0.85, P=0.66\right)$, indicating no association between the polymorphism and IHD risk in this population. Egger's test showed that publication bias was significant for $\mathrm{OR}_{2}$ but not for $\mathrm{OR}_{1}$ or $\mathrm{OR}_{3}\left(P=0.75\right.$ for $\mathrm{OR}_{1}$; $P=0.04$ for $\mathrm{OR}_{2}$ and $P=0.16$ for $\left.\mathrm{OR}_{3}\right)$. A sensitivity analysis including the study by Hubacek et al. ${ }^{7}$ involving 14,576 subjects did not change the results significantly (data not shown).

An initial analysis of a vulnerable plaque IHD subgroup including 10 European studies involving 8738 subjects yielded homogenous results (Table 2). The logistic regression with the fixed-effects model showed a nonsignificant overall gene effect $\left(\mathrm{LR}_{2}=0.33, P=0.85\right)$, indicating no association between the polymorphism and vulnerable plaque IHD. An inclusion of the study $^{7}$ showed very similar results (data not shown). A meta- analysis of other IHD subgroup including six studies involving 7157 subjects showed a similar outcome $\left(\mathrm{LR}_{2}=0.17, P=\right.$ $0.92)$.

\section{Meta-analysis of East Asian studies}

A Q-test of the six East Asian studies in HWE27,35,37,40,44,46 including 2546 subjects, showed a significant heterogeneity and published language was found to be the source of it (Q-test for $\mathrm{OR}_{1}, P=0.27$; Q-test for $\mathrm{OR}_{2}, P=0.05$, meta-regression $P<$ 0.01 ; Q-test for $\mathrm{OR}_{3}, P=0.67$ ). We further performed subgroup analyses of English or Chinese studies. A meta-analysis of the two English studies 27,35 including 1240 subjects showed a significant overall gene effect $\left(\mathrm{LR}_{2}=11.46, P<0.01\right)$. The estimated $\mathrm{OR}_{1}, \mathrm{OR}_{2}$, and $\mathrm{OR}_{3}$ suggested a recessive model (Table 2). The pooled OR under this genetic model indicated that East Asians who had the TT genotype were about 53\% more likely to have IHD (Table 2). A meta-analysis of the four Chinese studies involving 1306 subjects showed a significant overall gene effect $\left(\mathrm{LR}_{2}=36.54, P<0.01\right)$. The estimated ORs (Table 2) implied a codominant model. The pooled OR under this genetic model indicated that both TT and CT genotypes conferred increased susceptibility to the disease (Table 2). A sensitivity analysis including the study ${ }^{41}$ that deviated from HWE did not change the results significantly (data not shown).

A Q-test of the two East Asian studies published in English language journals on vulnerable plaque IHD 27,35 involving 1193 subjects showed a significant heterogeneity (Table 2) and the

Table 2 Estimated ORs for CD14 polymorphism and ischemic heart disease risk

\begin{tabular}{|c|c|c|c|c|c|c|c|}
\hline \multirow[b]{2}{*}{ Population } & \multicolumn{3}{|c|}{ ORs $(95 \% \mathrm{CI})$} & \multicolumn{3}{|c|}{$\begin{array}{l}P \text { value of } \mathrm{Q} \text {-test } \\
\text { for ORs }\end{array}$} & \multirow{2}{*}{$\begin{array}{l}\text { OR under indicating } \\
\text { Genetic model }\end{array}$} \\
\hline & $\mathrm{OR}_{1}$ & $\mathrm{OR}_{2}$ & $\mathrm{OR}_{3}$ & $\mathrm{OR}_{1}$ & $\mathrm{OR}_{2}$ & $\mathrm{OR}_{3}$ & \\
\hline \multicolumn{8}{|l|}{ Overall IHD } \\
\hline \multirow[t]{3}{*}{ European } & $1.03(0.92-1.15)$ & $1.05(0.95-1.15)$ & $0.98(0.89-1.09)$ & 0.43 & 0.56 & 0.23 & NS \\
\hline & $1.06(0.95-1.19)^{a}$ & $1.07(0.97-1.17)^{a}$ & $1.00(0.90-1.10)^{a}$ & $0.07^{a}$ & $0.37^{a}$ & $0.18^{a}$ & $\mathrm{NS}^{a}$ \\
\hline & $1.54(1.12-2.12)^{b}$ & $1.01(0.76-1.35)^{b}$ & $1.53(1.17-1.98)^{b}$ & $0.37^{b}$ & $0.70^{b}$ & $0.14^{b}$ & $1.53(1.20-1.96), P<0.01^{b, c}$ \\
\hline \multirow[t]{2}{*}{ East Asian } & $2.63(1.91-3.61)^{d}$ & $1.81(1.36-2.41)^{d}$ & $1.45(1.11-1.89)^{d}$ & $0.81^{d}$ & $0.42^{d}$ & $0.81^{d}$ & TT vs CC: $2.53(1.84-3.50), P<0.01^{d, e}$ \\
\hline & & & & & & & CT vs CC: $1.81(1.36-2.40), P<0.01^{d, e}$ \\
\hline \multicolumn{8}{|c|}{$\begin{array}{l}\text { Vulnerable plaque } \\
\text { IHD }\end{array}$} \\
\hline \multirow[t]{2}{*}{ European } & $1.02(0.90-1.16)$ & $1.03(0.93-1.15)$ & $0.99(0.89-1.11)$ & 0.25 & 0.39 & 0.12 & NS \\
\hline & $1.06(0.94-1.20)^{a}$ & $1.06(0.95-1.17)^{a}$ & $1.01(0.90-1.12)^{a}$ & $0.03^{a}$ & $0.23^{a}$ & $0.09^{a}$ & $\mathrm{NS}^{a}$ \\
\hline East Asian & $1.60(1.16-2.12)^{b}$ & $0.98(0.73-1.32)^{b}$ & $1.63(1.25-2.13)^{b}$ & $0.17^{b}$ & $0.27^{b}$ & $<0.01^{b}$ & NS \\
\hline \multicolumn{8}{|l|}{ Other IHD } \\
\hline European & $1.03(0.89-1.20)$ & $1.01(0.89-1.14)$ & $1.02(0.90-1.17)$ & 0.46 & 0.57 & 0.21 & NS \\
\hline \multirow[t]{2}{*}{ East Asian } & $2.46(1.75-3.46)^{d}$ & $1.71(1.27-2.31)^{d}$ & $1.44(1.08-1.92)^{d}$ & $0.72^{d}$ & $0.35^{d}$ & $0.81^{d}$ & TT vs CC: $2.35(1.68-3.31), P<0.01^{d, e}$ \\
\hline & & & & & & & CT vs CC: $1.70(1.26-2.29), P<0.01^{d, e}$ \\
\hline $\begin{array}{l}\text { Other IHD inclu } \\
\text { Sensitivity analy } \\
{ }^{b} \text { Included studies } \\
{ }^{c} \text { Pooled OR by r } \\
d_{\text {d }} \text { Included studies } \\
{ }^{e} \text { Pooled OR by c } \\
\text { OR, odds ratio; ? }\end{array}$ & $\begin{array}{l}\text { table angina pectoris a } \\
\text { y including the study b } \\
\text { published in English } \mathrm{j} \\
\text { ive model. } \\
\text { published in Chinese } \\
\text { linant model. } \\
\text { verall gene effect is no }\end{array}$ & $\begin{array}{l}\text { nd angiographic coron } \\
\text { y Hubacek et al. }{ }^{7} \\
\text { journals. } \\
\text { journals. }\end{array}$ & ary artery stenosis. & i. & & & \\
\hline
\end{tabular}


logistic regression with the random-effects model showed a nonsignificant overall gene effect, but the Chinese study ${ }^{39}$ on vulnerable plaque IHD reported a significant difference. The four Chinese studies $37,40,44,46$ on other IHD involving 1210 subjects showed a homogenous result (Table 2) and the logistic regression with the fixed-effects model showed a significant overall gene effect $\left(\mathrm{LR}_{2}=27.97, P<0.01\right)$. The pooled ORs (Table 2) indicated a codominant model. The estimated OR under this genetic model indicated that both TT and CT genotypes were associated with IHD risk (Table 2). An inclusion of the study ${ }^{42}$ that deviated from HWE did not change the result significantly (data not shown). However, the English study on other IHD showed a nonsignificant result. ${ }^{27}$

\section{DISCUSSION}

A large number of studies have been carried out to test the hypothesis that the CD14 C-260T polymorphism might be associated with the risk of IHD, but data have yielded conflicting results. There is concern that a positive association might be spurious; on the other hand that a negative result might be due to a small sample size. To produce a more precise result, we explored sources of heterogeneity by metaregression and performed meta-analyses in various populations to evaluate the association between the polymorphism and IHD risk.

Population stratification because of ethnicities may lead to inconsistency, especially when both allele frequencies and incidence rates of the diseases vary across ethnic groups. ${ }^{49}$ In the present study, results from populations with different genetic backgrounds were not the same. The combinations of the European studies showed nonsignificant results. We further found that the genotype distributions between the cases and the controls were almost the same (proportions of CC, CT, and TT were $26.88 \%, 49.60 \%, 23.18 \%$ and $27.24 \%, 49.02 \%, 23.35 \%$, respectively, for cases and controls) in this population. This indicates that the CD14 C(-260)T polymorphism might be of little importance for clinical practice and public health. The use of this polymorphism as a predictor for the risk of IHD may not be efficient and the screening utility of this genetic variant in asymptomatic individuals may not be warranted in European population. Results from East Asian studies were distinct and the pooled CD14-260T allele frequency of the controls showed a modest difference across ethnicities (European studies: 48.03\%; East Asian studies published in English language journals: 51.39\%; Chinese studies: $45.70 \%$; Indian study: $56.47 \%$ ). These may be explained by the different genetic backgrounds across ethnicities or a much smaller sample size in the East Asian and Indian studies.

Evidence of heterogeneity was found among East Asian studies and genetic backgrounds may not account for it. ${ }^{15}$ Published language was found to be the main source and a larger genetic effect was observed in most Chinese studies. Besides the small sample size, the plausible explanations may be that there is a publication bias in favor of positive results, selection bias in pursuing a significant finding for which the Chinese language may be a marker ${ }^{50}$; on the other hand, there may be differences in methods for selecting controls used in these studies. ${ }^{35,37,40,42,44,46}$ Subgroup analysis of English or Chinese studies indicated that the $-260 \mathrm{~T}$ allele was associated with overall IHD risk. However, there is chance, because of a relatively small sample size and publication bias ${ }^{50}$ this might lead to spurious results. The indicated genetic models ${ }^{21}$ were also different between English and Chinese studies involving East Asian subjects, for which the publication bias ${ }^{50}$ and relative small sample size may account. Interestingly, heterogeneity was not found in the analysis of overall IHD but was observed in the subgroup analysis of vulnerable plaque IHD of the two East Asian studies published in English language journals. This might be explained by the much smaller sample size of the study. ${ }^{27}$ Results from East Asian studies published in English language journals on overall IHD and vulnerable plaque IHD were also different, which was probably because the randomeffects model produced a more conservative result. Therefore, given that a combination of heterogeneous studies may lead to a less clear result, ${ }^{22}$ the potential risk of publication bias may lead to a deviation from the true effect size $\mathrm{e}^{50-54}$ and the relative small sample, results drawn from the East Asian studies should be interpreted with caution.

Evidence of publication bias was significant for $\mathrm{OR}_{2}$ but not for $\mathrm{OR}_{1}$ or $\mathrm{OR}_{3}$ among European studies. Many have argued that Egger's test ${ }^{26}$ has been likely to yield a false-positive result because of high type I error rate, especially when used for a binary outcome with a larger OR. ${ }^{55}$ Moreover, we further explored publication bias for all genetic models using Egger's test, and found that it was significant for the dominant model with a larger OR but not for the other genetic models with smaller ORs (data not shown). Therefore, the evidence of publication bias by Egger's test was probably false-positive.

Some limitations of the meta-analyses should be considered. First, the phenotypes that could be affected by both the lowpenetrance susceptibility gene ${ }^{56}$ and other risk factors of IHD (e.g., environment factors) might not be the same even though the genotypes were the same and this might lead to the misclassification bias. ${ }^{56,57}$ Second, the relatively small sample size, representativeness of controls, potential heterogeneity, and publication bias might affect results drawn from East Asian studies; in addition, there was only one study with a relatively small sample size involving an Indian population. Third, there might be eligible studies that were not published, not indexed by electronic databases, or published in the journals we did not cover. Lastly, a lack of individual participants' data has restricted further adjustments by other covariables, such as specific outcome, sex, smoking, diabetes, dyslipidemia, etc.

Despite limitations, the present study has suggested a possible association between the CD14 C-260T polymorphism and IHD risk in an East Asian population but not in European and Indian populations. In addition, there is a need for larger and more rigorous studies than is now customary, and a need to support the publication of negative results. There is also a greater need for updated genetic epidemiology quantitative systematic reviews with proper methodology, ${ }^{13}$ to help minimize random error, explore heterogeneity, address publication bias and enhance statistical power; thereby helping to better understand the association between the CD14 C-260T polymorphism and IHD risk.

\section{ACKNOWLEDGMENTS}

We thank the HuGENet ${ }^{\mathrm{TM}}$ for approving the title registration and providing guidelines for HuGE review and metaanalysis of genetic association studies. We thank Pin-Hu Liao and Deepak Rajbhandari for their help on revising the manuscript.

\section{REFERENCES}

1. Chen Y, Rollins J, Paigen B, Wang X. Genetic and genomic insights into the molecular basis of atherosclerosis. Cell Metab 2007;6:164-179.

2. Hawe E, Talmud PJ, Miller GJ, Humphries SE. Family history is a coronary heart disease risk factor in the Second Northwick Park Heart Study. Ann Hum Genet 2003;67:97-106. 
3. Ross R. Atherosclerosis - an inflammatory disease. N Engl J Med 1999;340: $115-126$,

4. Becker AE, de Boer OJ, van Der Wal AC. The role of inflammation and infection in coronary artery disease. Annu Rev Med 2001;52:289-297.

5. Muhlestein JB, Anderson JL. Chronic infection and coronary artery disease. Cardiol Clin 2003;21:333-362.

6. Hansson GK. Inflammation, atherosclerosis, and coronary artery disease. N Engl J Med 2005;352:1685-1695.

7. Hubacek JA, Rothe G, Pit'ha J, et al. C(-260) $\rightarrow$ T polymorphism in the promoter of the CD14 monocyte receptor gene as a risk factor for myocardial infarction. Circulation 1999;99:3218-3220. [Erratum, Circulation 1999;100: 2550.]

8. Goyert S, Ferrero E, Rettig W, Yenamandra A, Obata F, Le Beau M. The CD14 monocyte differentiation antigen maps to a region encoding growth factors and receptors. Science 1988;239:497-500.

9. Fernandez-Real JM, Broch M, Richart C, Vendrell J, Lopez-Bermejo A, Ricart W. CD14 monocyte receptor, involved in the inflammatory cascade, and insulin sensitivity. J Clin Endocrinol Metab 2003;88:1780-1784.

10. Baldini M, Lohman IC, Halonen M, Erickson RP, Holt PG, Martinez FD. A Polymorphism in the $5^{\prime}$ flanking region of the CD14 gene is associated with circulating soluble CD14 levels and with total serum immunoglobulin E. Am J Respir Cell Mol Biol 1999;20:976-983.

11. LeVan TD, Bloom JW, Bailey TJ, et al. A common single nucleotide polymorphism in the CD14 promoter decreases the affinity of Sp protein binding and enhances transcriptional activity. J Immunol 2001;167:5838-5844.

12. Rosamond W, Flegal K, Furie K, et al. Heart disease and stroke statistics2008 update: a report from the American Heart Association Statistics Committee and Stroke Statistics Subcommittee. Circulation 2008;117:e25-e146.

13. Little J, Higgins JPT, editors. The HuGENet ${ }^{\mathrm{TM}}$ HuGE review handbook, version 1.0. Available at: http://www.hugenet.org.uk. Accessed December 2, 2008.

14. Mottl AK, Shoham DA, North KE. Angiotensin II type 1 receptor polymorphisms and susceptibility to hypertension: a HuGE review. Genet Med 2008; 10:560-574.

15. Ioannidis JP, Ntzani EE, Trikalinos TA. 'Racial' differences in genetic effects for complex diseases. Nat Genet 2004;36:1312-1318

16. Kwong RY, Schussheim AE, Rekhraj S, et al. Detecting acute coronary syndrome in the emergency department with cardiac magnetic resonance imaging. Circulation 2003;107:531-537.

17. Casas JP, Bautista LE, Humphries SE, Hingorani AD. Endothelial nitric oxide synthase genotype and ischemic heart disease: meta-analysis of 26 studies involving 23028 subjects. Circulation 2004;109:1359-1365.

18. Richards M, Nicholls MG, Espiner EA, et al. Comparison of B-type natriuretic peptides for assessment of cardiac function and prognosis in stable ischemic heart disease. J Am Coll Cardiol 2006;47:52-60.

19. Yu W, Gwinn M, Clyne M, Yesupriya A, Khoury MJ. A navigator for human genome epidemiology. Nat Genet 2008;40:124-125.

20. Thakkinstian A, McEvoy M, Minelli C, et al. Systematic review and metaanalysis of the association between $\beta_{2}$-adrenoceptor polymorphisms and asthma: a HuGE review. Am J Epidemiol 2005;162:201-211.

21. Thakkinstian A, McElduff P, D'Este C, Duffy D, Attia J. A method for meta-analysis of molecular association studies. Stat Med 2005;24:1291-1306.

22. Higgins JP, Thompson SG, Deeks JJ, Altman DG. Measuring inconsistency in meta-analyses. BMJ 2003;327:557-560.

23. Thompson SG. Why sources of heterogeneity in meta-analysis should be investigated. BMJ 1994;309:1351-1355.

24. Thompson SG, Smith TC, Sharp SJ. Investigating underlying risk as a source of heterogeneity in meta-analysis. Stat Med 1997;16:2741-2758

25. Thompson SG, Sharp SJ. Explaining heterogeneity in meta-analysis: a comparison of methods. Stat Med 1999;18:2693-2708.

26. Egger M, Davey Smith G, Schneider M, Minder C. Bias in meta-analysis detected by a simple, graphical test. BMJ 1997;315:629-634

27. Shimada K, Watanabe Y, Mokuno H, Iwama Y, Daida H, Yamaguchi H. Common polymorphism in the promoter of the CD14 monocyte receptor gene is associated with acute myocardial infarction in Japanese men. Am J Cardiol 2000;86:682-684

28. Avanzas P, Arroyo-Espliguero R, Cosin-Sales J, et al. Markers of inflammation and multiple complex stenoses (pancoronary plaque vulnerability) in patients with non-ST segment elevation acute coronary syndromes. Heart 2004; $90: 847-852$.

29. Schoenhagen P, Tuzcu EM, Ellis SG. Plaque vulnerability, plaque rupture, and acute coronary syndromes: (multi)-focal manifestation of a systemic disease process. Circulation 2002;106:760-762.

30. Unkelbach K, Gardemann A, Kostrzewa M, Philipp M, Tillmanns H, Haberbosch W. A new promoter polymorphism in the gene of lipopolysaccharide receptor CD14 is associated with expired myocardial infarction in patients with low atherosclerotic risk profile. Arterioscler Thromb Vasc Biol 1999;19: 932-938.

31. Zee RY, Lindpaintner K, Struk B, Hennekens CH, Ridker PM. A prospective evaluation of the CD14 C(-260)T gene polymorphism and the risk of myocardial infarction. Atherosclerosis 2001;154:699-702.
32. Koch W, Kastrati A, Mehilli J, von Beckerath N, Schomig A. CD14 gene$159 \mathrm{C} / \mathrm{T}$ polymorphism is not associated with coronary artery disease and myocardial infarction. Am Heart $J$ 2002;143:971-976.

33. Koenig W, Khuseyinova N, Hoffmann MM, et al. CD14 C(-260) $\rightarrow$ T polymorphism, plasma levels of the soluble endotoxin receptor CD14, their association with chronic infections and risk of stable coronary artery disease. J Am Coll Cardiol 2002;40:34-42.

34. Nauck M, Winkelmann BR, Hoffmann MM, Bohm BO, Wieland H, Marz W. $\mathrm{C}(-260) \mathrm{T}$ polymorphism in the promoter of the CD14 gene is not associated with coronary artery disease and myocardial infarction in the Ludwigshafen Risk and Cardiovascular Health (LURIC) study. J Am Coll Cardiol 2002;90: $1249-1252$.

35. Hohda S, Kimura A, Sasaoka T, et al. Association study of CD14 polymorphism with myocardial infarction in a Japanese population. Jpn Heart $J$ 2003;44:613-622.

36. Longobardo MT, Cefalu AB, Pezzino F, et al. The $\mathrm{C}(-260) \rightarrow \mathrm{T}$ gene polymorphism in the promoter of the CD14 monocyte receptor gene is not associated with acute myocardial infarction. Clin Exp Med 2003;3:161-165.

37. Pan M, Gu DF, Chen F, et al. C(-260)T polymorphism in CD14 gene promoter and its association with coronary heart disease in Chinese population. Chin J Misdiagnosis 2003;3:1458-1459.

38. Morange PE, Tiret L, Saut N, et al. TLR4/Asp299Gly, CD14/C-260T, plasma levels of the soluble receptor CD14 and the risk of coronary heart disease: the PRIME Study. Eur J Hum Genet 2004;12:1041-1049.

39. Arroyo-Espliguero R, El-Sharnouby K, Vazquez-Rey E, Kalidas K, Jeffery S, Kaski JC. CD14 C(-260)T promoter polymorphism and prevalence of acute coronary syndromes. Int J Cardiol 2005;98:307-312.

40. Li Y, Xiong XQ, Zhang PA, Ming KH. Association of C-159T polymorphism in promoter region of CD14 and coronary heart disease. Zhonghua Yi Xue Yi Chuan Xue Za Zhi 2005;22:687-690.

41. Morange PE, Saut N, Alessi MC, et al. Interaction between the C-260T polymorphism of the CD14 gene and the plasma IL-6 concentration on the risk of myocardial infarction: the HIFMECH study. Atherosclerosis 2005; 179:317-323

42. Hu R, Cheng LX, He MA, Wu TC. The polymorphism in the promoter of the CD14 monocyte receptor gene is a risk factor for coronary heart disease in Wuhan population. Chin J Gen Geriatr Heart Brain Vessel Dis 2006;8:184186.

43. Banerjee I, Pandey U, Hasan OM, Parihar R, Tripathi V, Ganesh S. Association between inflammatory gene polymorphisms and coronary artery disease in an Indian population. $J$ Thromb Thrombolysis 2009;27:88-94.

44. Li L, Zhang K, Qiu F, et al. Association of C (-159)T polymorphism in the promoter of CD14 gene with coronary heart disease in Han population of Jiangsu province. J Clin Rehabil Tissue Eng Res 2007;11:8749-8752.

45. Lorenzova A, Stanek V, Gebauerova M, et al. High-sensitivity C-reactive protein concentration in patients with myocardial infarction-environmental factors, and polymorphisms in interleukin-10 and CD14 genes. Clin Chem Lab Med 2007;45:855-861.

46. Xie RX, Bu-Ai JE, Ma YT, Ma X, Fu ZY, Jia ZH. The polymorphism in the promoter of CD14 gene and its association with coronary heart disease and blood lipid levels in Chinese Han and Uighur population. Chin J Cardiovasc Rev 2008;6:403-406.

47. Wei YS, Liu YG, Tang RG, et al. Association between the polymorphism of the CD14 gene promoter and coronary heart disease. J Fourth Mil Med Univ 2006;27:630-633.

48. Multinational monitoring of trends and determinants in cardiovascular diseases: "MONICA Project." Manual of operations WHO/MNC 82.2. 1983.

49. McAteer JB, Prudente S, Bacci S, et al. The ENPP1 K121Q polymorphism is associated with type 2 diabetes in European populations: evidence from an updated meta-analysis in 42,042 subjects. Diabetes 2008;57:1125-1130.

50. Pan Z, Trikalinos TA, Kavvoura FK, Lau J, Ioannidis JP. Local literature bias in genetic epidemiology: an empirical evaluation of the Chinese literature. PLoS Med 2005;2:e334.

51. Rothstein HR, Sutton AJ, Borenstein M. Publication bias in meta-analysis. Prevention, assessment and adjustments. Sussex: Wiley, 2005.

52. Thornton A, Lee P. Publication bias in meta-analysis: its causes and consequences. J Clin Epidemiol 2000;53:207-216.

53. Sterne JA, Gavaghan D, Egger M. Publication and related bias in metaanalysis: power of statistical tests and prevalence in the literature. $J$ Clin Epidemiol 2000;53:1119-1129.

54. Sterne JA, Egger M, Smith GD. Systematic reviews in health care: investigating and dealing with publication and other biases in meta-analysis. $B M J$ 2001;323:101-105.

55. Peters JL, Sutton AJ, Jones DR, Abrams KR, Rushton L. Comparison of two methods to detect publication bias in meta-analysis. JAMA 2006;295:676680 .

56. Watkins H, Farrall M. Genetic susceptibility to coronary artery disease: from promise to progress. Nat Rev Genet 2006;7:163-173.

57. Pavia M, Pileggi C, Nobile CG, Angelillo IF. Association between fruit and vegetable consumption and oral cancer: a meta-analysis of observational studies. Am J Clin Nutr 2006;83:1126-1134. 